
About IJMA [last updated July, $\left.1^{\text {st }}, 2021\right]$

$\checkmark$ International Journal of Medical Arts is the Official Journal of the Damietta Faculty of Medicine, AlAzhar University, Egypt

$\checkmark$ It is an International, Open Access, Double-blind, Peer-reviewed Journal

$\checkmark$ Published four times a year

$\checkmark$ The First Issue was published in July 2019

$\checkmark$ Published under the following license: Creative Commons Attribution-ShareAlike 4.0 International Public License (CC BY-SA 4.0). It had updated from the Creative Commons license [CC BY] in volume 2, Issue 4, October 2020 About IJMA

$\checkmark$ The Egyptian Knowledge Bank hosts the web site of IJMA

$\checkmark$ The Egyptian Knowledge Bank supports IJMA

$\checkmark$ IJMA follows the regulations of the International Committee of Medical Journal Editors

$\checkmark$ IJMA is indexed in the "Directory of Open Access Journals" [15 January 2021].

$\checkmark$ IJMA is indexed in JGate [29-6-2021]

$\checkmark$ IJMA is a member of the International Society of Managing and Technical Editors

$\checkmark$ Listed in "Index Copernicus", "Publons", "Academic resource index [ResearchBib]", "Electronics journal library", "Eurasian Scientific Journal Index", and "Citefactor"

$\checkmark$ IJMA introduced to the search engine [BASE] through DOAJ
Click image to reach the page

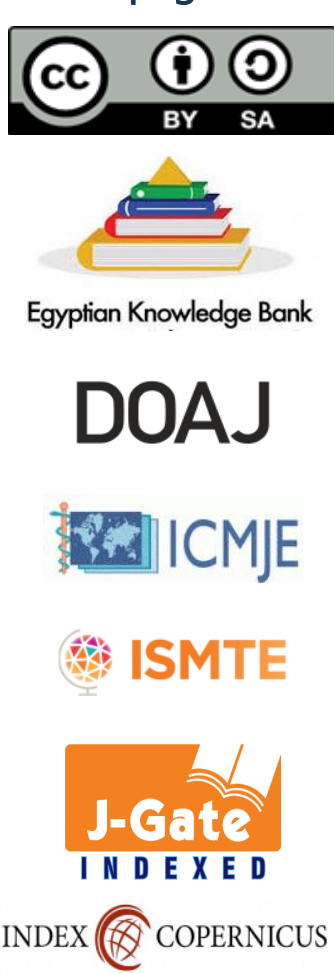

publons

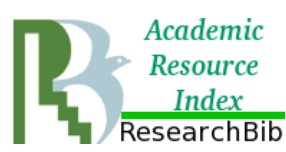

\section{EZ3 \\ .}

ESJII

CiteFactor

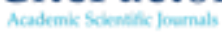

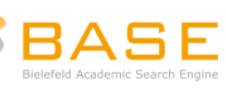




Available online at Journal Website
https://ijma.journals.ekb.eg/
Main subject [Pharmacology]

Original Article

\title{
Potential Effect of Curcumin versus Atorvastatin on Hepatic and Metabolic Changes in Rat Model of Metabolic Syndrome
}

\author{
Alaaeldin Ahmed Eissa [1], Abdelateef Said Abdelateef [2], Hassan Mahmoud Elkotby [2] \\ Department of Pharmacology, Damietta Faculty of Medicine, Al-Azhar University, Egypt [1]. \\ Department of Pharmacology, Faculty of Medicine, Al-Azhar University, Egypt [2]. \\ Corresponding author: Alaaeldin Ahmed Eissa \\ Email: dralaaeissa2016@gmail.com
}

Submission date: February 16, 2021; Revision date: May 11, 2021; Acceptance date: May 13, 2021

DOI: 10.21608/IJMA.2021.61857.1267

DOAJ

\section{ABSTRACT}

Background: Metabolic syndrome is defined as a cluster of metabolic disorders, including hypertension, insulin resistance, dyslipidemia, diabetes, cardiovascular disease and abdominal [central] obesity. It is also found under different names, such as syndrome $X$, "deadly quartet" and insulin resistance syndrome.

The aim of the work: to investigate the potential effect of curcumin and compare it with the effect of metformin and atorvastatin on hepatic and metabolic changes in metabolic syndrome.

Materials and Methods: Fifty male Sprague-Dawley [8 weeks old] weighting 150-200 g obtained from animal house of the department of pharmacology, Al-Azhar Faculty of Medicine. Rats were kept in regular dark - light cycle with free access to groups [specific diet and water] that were renewed daily and were observed for water intake, food intake, changes in body weight and abdominal circumference during 16-week study period.

Results: Histopathological changes after administration of high carbohydrate high fat [HCHF] diet, revealed fatty changes, ballooning degeneration [vacuoles] and fibrosis. Infiltration by large numbers of inflammatory cells was detected in the portal area and there was an inflammatory reaction dividing the hepatic parenchyma into lobules. On the other side, the treated rats with curcumin showed improved inflammation [few inflammatory cells, slight ballooning and fibrosis, but still present moderate steatosis in liver samples. The atorvastatin group revealed comparable results to the curcumin group. However, when combined together, they were able to restore hepatic tissue to nearly its normal structure.

Conclusions: Combination therapy by curcumin and atorvastatin was more effective in the management of non-alcoholic fatty liver/nonalcoholic steatohepatitis [NAFL/NASH]. However, further studies are required to evaluate the applicability of the present results in human beings and to judge the safety and efficacy of curcumin, atorvastatin and their combination.

Keywords: Curcumin; Atorvastatin; Combination; Metabolic Syndrome.

This is an open-access article registered under the Creative Commons, ShareAlike 4.0 International license [CC BY-SA 4.0] [https://creativecommons.org/licenses/by-sa/4.0/legalcode.

Citation: Eissa AA, AbdElateef AS, Elkotby HM. Potential Effect of Curcumin versus Atorvastatin on Hepatic and Metabolic Changes in Rat Model of Metabolic Syndrome. IJMA 2021; 3 [3] July-September: 1507-1515. [DOI: 10.21608/IJMA.2021.61857.1267].

${ }^{*}$ Main subject and any subcategories have been classified according to the research topic. 


\section{INTRODUCTION}

According to the National Cholesterol Education Program's Adult Treatment Panel III [ATPIII], metabolic syndrome is a combination of multiple risk factors that increases an individual's chance to develop cardio-

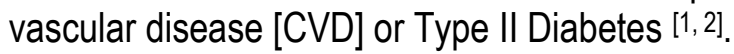

Curcuma longa [turmeric] is a rhizomatous herbaceous perennial plant of the ginger family [Zingiberaceae]. The deep orange-yellow powder known as turmeric is prepared from boiled and dried rhizomes of the plant. It has been commonly used as spice [3].

Presently, a growing interest in herbal medicine has prompted a large number of scientific investigations about the biological and pharmacological properties of curcuma longa extract main component curcumin, which exerts several biological actions [4].

The statins are a class of drugs, which act to lower total cholesterol and low-density lipoprotein [LDL] levels by reducing hepatic cholesterol production through inhibition of hydroxyl-methyl-glutamyl Co-A [HMG-COA] reductase and a reduced cardiovascular disease [CVD] incidence [5].

\section{THE AIM OF THE WORK}

The current study aimed to investigate the potential effect of curcumin and compare it with the effect of metformin and atorvastatin on hepatic and metabolic changes in metabolic syndrome

\section{MATERIALS AND METHODS:}

\section{Drugs and chemicals}

Curcumin [purity 99\%] was purchased from Sigma-Aldrich Chemical Company [Cairo, Egypt] in the form of a bottle containing $100 \mathrm{gm}$ of yellow powder [Catalog number C1386]. The required daily dose was weighted, suspended in $2 \mathrm{ml}$ corn oil and given orally through gastric gavage at a dose of $200 \mathrm{mg} / \mathrm{Kg} / \mathrm{bw}$ [6]. Atorvastatin calcium salt trihydrate in the form of pure powder in glass bottle was obtained from Sigma [Sigma Chemical Co., St. Louis, MO, USA]. The daily dose was prepared and administered by orally through gastric gavage in a dose of $30 \mathrm{mg} / \mathrm{kg} /$ day.

\section{Animals}

Fifty male Sprague-Dawley [8 weeks old] weighing $150-200 \mathrm{~g}$ were obtained from the animal house of the department of pharmacology, Al-Azhar Faculty of Medicine. Rats were kept in a regular dark - light cycle with free access to groups [specific diet and water] that were renewed daily and were observed for water intake, food intake, changes in body weight and abdominal circumference during the 16 weeks study duration.

All group-specific diet was prepared in our laboratory. The cornstarch [CS] diet was prepared by mixing cornstarch- powdered rat feed, Hubble, Mendel and Wakeman salt mixture, and water. The cornstarch was replaced with condensed milk, fructose, and beef tallow in the high carbohydrate, high fat [HCHF] diet. The drinking water for the $\mathrm{HCHF}$ diet groups was augmented with fructose. HCHF diet contained $50 \%$ carbohydrate [mainly fructose] and $24 \%$ fat [mainly beef tallow] with $25 \%$ fructose in drinking water. Control rats fed a corn starch-rich diet contained 68\% carbohydrate [mainly cornstarch] and $0.7 \%$ fat. Drugs were given once daily at 10:00 AM to 11:00 AM for the last 8 weeks of the experiment ${ }^{[7]}$

\section{Experimental design}

Group 1: Control corn starch [16- weeks] group: rats in this group were fed corn starch diet throughout the 16-weeks protocol and served as the control normal group.

Group 2: High carbohydrate, high fat [16-weeks] group. Rats in this group were fed HCHF diet throughout 16 weeks protocol served as the control diseased group [8].

Group 3: Atorvastatin $30 \mathrm{mg} / \mathrm{kg} /$ day treated high carbohydrate high fat group. Rats in this group were fed HCHF diet throughout 16-weeks, treated with atorvastatin $30 \mathrm{mg} / \mathrm{kg}$ day administered by gavage for the last 8 weeks of the protocol [9].

Group 4: Curcumin-treated group [200 mg/kg/day]. Rats in this group were fed HCHF diet throughout 16weeks, treated with curcumin $200 \mathrm{mg} / \mathrm{kg} / \mathrm{day}$ administered by gavage for the last 8 weeks of the protocol. 
Group 5: Curcumin and atorvastatin- treated group. Rats in this group were fed HCHF diet throughout 16weeks, treated with curcumin $200 \mathrm{mg} / \mathrm{kg} / \mathrm{day}$ and atorvastatin $30 \mathrm{mg} / \mathrm{kg}$ administered by gavage for the last 8 weeks of the protocol.

\section{Collection of blood samples}

At the end of the experiment, laparotomy was done and blood samples were collected by cardiac puncture. Blood samples were collected with $10 \mathrm{IU}$ of heparin left for 10 minutes, and then centrifuged for 10 minutes at $4000 \mathrm{~g}$ to obtain plasma and serum, respectively, which are stored at $-20^{\circ} \mathrm{C}$ until biochemical analysis.

We investigated the effect of HCHF diet feeding for 16-weeks on plasma glucose, serum adiponectin, final body weight [FBW], final abdominal circumference [FAC], food intake [FI], water intake [WI], serum aspartate transaminase [AST], serum alanine transaminase $[\mathrm{ALT}]$, plasma total cholesterol [TC], plasma triglycerides [TG], plasma high-density lipoprotein $[\mathrm{HDL}]$ cholesterol and plasma low -density lipoprotein [LDL] cholesterol. These biological variables were measured to assess the pathophysiological changes prior to drug intervention and compared with their corresponding in cornstarch [CS] fed rats for the same period [16-weeks].

\section{Preparation of liver homogenate}

For all groups, the liver was harvested, cut, coded and immediately washed in $0.9 \% \mathrm{NaCl}$ and embedded in $10 \%$ buffered formalin for three days. Formalin solution was changed daily to prevent the presence of blood traces in the tissue. After that, liver sections were sent for pathological evaluations. The liver specimens were then dehydrated and fixed in paraffin wax. Sections of $5-\mu \mathrm{m}$ thickness were cut, deparaffinized with xylene and then rehydrated through decreasing concentrations of ethanol for staining with hematoxylin and eosin. Microscopic examination of these liver samples was done at $10 x$ and $40 x$ power of magnification for steatosis, inflammation and fibrosis assessment according to Panchal et al. [10].

Mild steatosis was recorded as less than $25 \%$ of hepatocytes showed fatty changes in liver sections in 10 high-power field. Moderate steatosis defined as more than $50 \%$ of hepatocytes in sections in 10 high- power field showed fatty changes. Sever steatosis was defined as nearly all hepatocytes showed massive fatty changes in sections in 10 high-power fields. Hepatic inflammation was defined as the ratio of the area of inflammatory foci to the total area of the section [11].

\section{Statistical analysis}

All statistical calculations were done using computer programs. Microsoft Excel version 10 and SPSS [statistical package for the social science version 20.00]. The One-way analysis of variance [ANOVA] and Post Hoc- least significant differences [LSD] tests were used to compare numerical data, which was presented using mean \pm standard deviation [SD]. Additionally, paired samples " $\mathrm{t}$ " test used to compare between one value at two different points of time. However, qualitative data were presented as frequency and percentages and Chi square test was used to check for association. $P$ value $<0.05$ was set as a significant.

\section{RESULTS}

In this study, feeding the rats with HCHF diet for 16 weeks increased plasma glucose level from $4.77 \pm 0.8$ $\mathrm{mmoL} / \mathrm{L}$ to $6.82 \pm 1.3 \mathrm{mmoL} / \mathrm{L}[\mathrm{p}<0.05]$. Also, in the rat group treated with curcumin, Plasma glucose level decreased from $6.82 \pm 1.3 \mathrm{mmoL} / \mathrm{L}$ to $6.1 \pm 1.2 \mathrm{mmol} / \mathrm{l}$. In rats treated with curcumin plus atorvastatin, plasma glucose levels decreased from $6.82 \pm 1.3 \mathrm{mmoL} / \mathrm{L}$ to $5.61 \pm 1.2 \mathrm{mmoL} / \mathrm{L}[\mathrm{p}<0.05$ ] [table 1 , figure 1].

Feeding rats with $\mathrm{HCHF}$ diet for 16 -weeks, plasma adiponectin decreased significantly from $65.50 \pm 16.8$ $\mathrm{pg} / \mathrm{ml}$ to $9.83 \pm 2.6 \mathrm{pg} / \mathrm{ml}$; while in atorvastatin treated group, adiponectin increased significantly from $9.83 \pm$ $2.6 \mathrm{pg} / \mathrm{ml}$ to $37.00 \pm 10.2 \mathrm{pg} / \mathrm{ml}$.

In rats treated with curcumin, plasma adiponectin significantly increased from $9.83 \pm 2.6 \mathrm{pg} / \mathrm{ml}$ to $41.00 \pm$ $9.1 \mathrm{pg} / \mathrm{ml}$, while in combined treatment group, plasma adiponectin increased significantly from $9.83 \pm 2.6 \mathrm{pg} / \mathrm{ml}$ to $42.21 \pm 10.2 \mathrm{pg} / \mathrm{ml}$ [Table 1, Figure 2].

Rats on HCHF diet for 16-weeks showed significant increase of final body weight [FBW] from 245.0 \pm 34.6 $\mathrm{gm}$ to $340.0 \pm 58.6 \mathrm{gm}$. Final abdominal circumference [FAC] significantly increased from $16.50 \pm 2.7 \mathrm{~cm}$ to $22.12 \pm 4.60 \mathrm{~cm}$. In rats treated with atorvastatin, FBW 
decreased from $340.00 \pm 58.6 \mathrm{gm}$ to $327.50 \pm 49.3 \mathrm{gm}$. In addition, FAC significantly decreased from $22.12 \pm$ $4.60 \mathrm{~cm}$ to $17.2 \pm 2.8 \mathrm{~cm}$. In curcumin treated rats, FBW was significantly decreased from $340.00 \pm 58.6$ $\mathrm{gm}$ to $300 \pm 41.3 \mathrm{gm}$, and FAC significantly decreased from $22.12 \pm 4.60 \mathrm{~cm}$ to $17.1 \pm 2.7 \mathrm{~cm}$. Furthermore, in combined treatment group, FBW significantly decreased from $340.0 \pm 58.6 \mathrm{gm}$ to $285.1 \pm 41.3 \mathrm{gm}$. FAC significantly decreased from $22.12 \pm 4.60 \mathrm{~cm}$ to $16.9 \pm 2.8 \mathrm{~cm}$ [Table 2, figures 3,4$]$

Results of liver enzymes throughout the study duration and comparison between groups was presented in detail in table 3 and figure 5; while results of lipid profile was presented in table 4 and figure 6 . Other laboratory data and blood pressure were presented in subsequent table [5] and figures 7 and 8.

\section{Histopathological examination of hepatic tissue specimens:}

- The CS group: microscopic examination showed no histopathological alterations. Normal histological structure of the central vein and surrounding hepatocytes [Figure 9]

- The HCHF group: liver showed necrotic lesions, fatty infiltration [F], mild inflammatory cell infiltration [L], dilatation of central vein [V] with vascular congestion $[\mathrm{C}]$, disorganization of hepatic cords $[\mathrm{H}]$, and dilatation of blood sinusoid [S] [Figure 10].

- The atorvastatin group: there was mild restoration of hepatic plate organization $[\mathrm{H}]$, low grade of central vein [V] dilatation, moderate congestion $[\mathrm{C}]$, moderate degree of fatty cell infiltration $[F]$, few inflammatory cell infiltration [L], and moderate dilatation of blood sinusoid [S] [Figure 11].

- The curcumin group: there was improvement of inflammatory reaction [few inflammatory cells, slight ballooning and fibrosis], but still present moderate steatosis in liver samples [Figure 12].

- Curcumin plus atorvastatin: there was small vacuoles in the cytoplasm of hepatocytes with little fatty change [Figure 13].

Table [1]: Effect of curcumin, Atorvastatin and combination of them on plasma glucose

\begin{tabular}{|l|c|c|c|c|c|c|c|}
\hline & $\begin{array}{c}\text { CS 16w } \\
{[\mathrm{n}=10]}\end{array}$ & $\begin{array}{c}\text { HCHF } \\
{[\mathrm{n}=10]}\end{array}$ & $\begin{array}{c}\text { Curcumin } \\
{[\mathrm{n}=10]}\end{array}$ & $\begin{array}{c}\text { A Tor } \\
{[\mathrm{n}=10]}\end{array}$ & $\begin{array}{c}\text { Curcumin }+\mathrm{A} \text { Tor } \\
{[\mathrm{n}=10]}\end{array}$ & $\mathrm{F}$ & $\mathrm{p}$-value \\
\hline FBG [mmol/L] & $4.63 \pm 1.20$ & $7.78 \pm 1.60^{\mathrm{a}}$ & $6.10 \pm 1.20^{\mathrm{ab}}$ & $5.95 \pm 1.50^{\mathrm{ab}}$ & $5.61 \pm 1.20^{\mathrm{b}}$ & 7.132 & $<0.001$ \\
\hline Adiponectin $[\mathrm{pg} / \mathrm{mL}]$ & $65.50 \pm 16.80$ & $9.83 \pm 2.60^{\mathrm{a}}$ & $41.00 \pm 9.10^{\mathrm{ab}}$ & $37.00 \pm 10.20^{\mathrm{ab}}$ & $44.12 \pm 10.20^{\mathrm{ab}}$ & 34.191 & $<0.001$ \\
\hline
\end{tabular}

One Way Analysis of Variance [F]; Post HOC Test, LSD: a. Significant difference with CS 16w; b. Significant difference with HCHF; c. Significant difference with curcumin d. Significant difference with A Tor; This table shows statistically significant difference between groups according to FBG and adiponectin.

Table [2]: Effect of curcumin, Atorvastatin and combination of them on final body weight [FBW], final abdominal circumference [FAC], food intake [FI] and water intake [WI].

\begin{tabular}{|l|c|c|c|c|c|c|c|}
\hline Parameters & $\begin{array}{c}\text { CS 16w } \\
{[\mathrm{n}=10]}\end{array}$ & $\begin{array}{c}\mathrm{HCHF} \\
{[\mathrm{n}=10]}\end{array}$ & $\begin{array}{c}\text { Curcumin } \\
{[\mathrm{n}=10]}\end{array}$ & $\begin{array}{c}\text { Ator } \\
{[\mathrm{n}=10]}\end{array}$ & Curcumin + Ator $[\mathrm{n}=10]$ & ANOVA & $\mathrm{p}$-value \\
\hline FBW $[\mathrm{gm}]$ & $245.00 \pm 34.60$ & $340.00 \pm 58.60^{\mathrm{a}}$ & $300.00 \pm 41.30 \mathrm{ab}$ & $327.50 \pm 49.30^{\mathrm{a}}$ & $285.10 \pm 41.30^{\mathrm{abd}}$ & 6.686 & $<0.001$ \\
\hline FAC $[\mathrm{cm}]$ & $16.50 \pm 2.70$ & $22.12 \pm 4.60^{\mathrm{a}}$ & $17.10 \pm 2.70^{\mathrm{b}}$ & $17.20 \pm 2.80^{\mathrm{b}}$ & $16.90 \pm 2.80^{\mathrm{b}}$ & 5.318 & $<0.001$ \\
\hline $\mathrm{FI}[\mathrm{gm} / \mathrm{d}]$ & $29.83 \pm 8.60$ & $21.00 \pm 5.40^{\mathrm{a}}$ & $23.20 \pm 4.10^{\mathrm{a}}$ & $21.00 \pm 5.30^{\mathrm{a}}$ & $17.90 \pm 5.10^{\mathrm{ac}}$ & 5.735 & $<0.001$ \\
\hline WI [mL/d] & $36.83 \pm 9.70$ & $22.50 \pm 6.40^{\mathrm{a}}$ & $24.50 \pm 5.40^{\mathrm{a}}$ & $22.17 \pm 5.80^{\mathrm{a}}$ & $23.00 \pm 5.20^{\mathrm{a}}$ & 8.630 & $<0.001$ \\
\hline
\end{tabular}
with A Tor; This table shows statistically significant difference between groups according to FBW, FAC, FI and WI.

Table [3]: Effect of curcumin, Atorvastatin and combination of them on aspartate transaminase [AST] and alanine Transaminase [ALT]

\begin{tabular}{|l|l|l|l|l|l|l|l|}
\hline Parameters & $\begin{array}{l}\text { CS 16w } \\
{[n=10]}\end{array}$ & $\begin{array}{l}\text { HCHF } \\
{[n=10]}\end{array}$ & $\begin{array}{l}\text { Curcumin } \\
{[n=10]}\end{array}$ & $\begin{array}{l}\text { A Tor } \\
{[n=10]}\end{array}$ & $\begin{array}{l}\text { Curcumin+Ator } \\
{[n=10]}\end{array}$ & ANOVA & $p$-value \\
\hline AST [u/L] & $10.00 \pm 2.30$ & $35.00 \pm 9.40$ a & $25.00 \pm 6.50$ ab & $31.83 \pm 8.50$ ac & $24.97 \pm 5.50$ abd & 19.453 & $<0.001$ \\
\hline ALT [u/L] & $6.00 \pm 1.70$ & $27.33 \pm 8.30$ a & $20.61 \pm 5.60$ ab & $22.67 \pm 6.90$ ab & $20.91 \pm 5.60$ ab & 17.629 & $<0.001$ \\
\hline
\end{tabular}

Using: One Way Analysis of Variance; Post HOC Test, LSD: a. Significant difference with CS 16w; b. Significant difference with HCHF; c. Significant difference with curcumin; d. Significant difference with A Tor This table shows statistically significant difference between groups according to ALT, AST. 
Table [4]: Effect of curcumin, Atorvastatin and combination of them on total cholesterol [TC], Triglyceride [TG], High- density lipoprotein cholesterol [HDL] and low- density lipoprotein cholesterol [LDL].

\begin{tabular}{|l|l|l|l|l|l|c|c|}
\hline Parameters & \multicolumn{1}{|c|}{$\begin{array}{c}\text { CS 16w } \\
{[\mathrm{n}=10]}\end{array}$} & $\begin{array}{c}\text { HCHF } \\
{[\mathrm{n}=10]}\end{array}$ & $\begin{array}{c}\text { Curcumin } \\
{[\mathrm{n}=10]}\end{array}$ & $\begin{array}{c}\text { A Tor } \\
{[\mathrm{n}=10]}\end{array}$ & $\begin{array}{c}\text { Curcumin }+ \text { Ator } \\
{[\mathrm{n}=10]}\end{array}$ & ANOVA & p-value \\
\hline TC $[\mathrm{mg} / \mathrm{dL}]$ & $114.50 \pm 21.40$ & $251.20 \pm 32.30 \mathrm{a}$ & $195.20 \pm 40.40 \mathrm{ab}$ & $152.83 \pm 43.80 \mathrm{abc}$ & $140.40 \pm 33.50 \mathrm{abc}$ & 23.235 & $<0.001$ \\
\hline TG $[\mathrm{mg} / \mathrm{dL}]$ & $100.30 \pm 23.70$ & $170.83 \pm 42.90 \mathrm{a}$ & $145.17 \pm 33.30 \mathrm{a}$ & $125.17 \pm 31.40 \mathrm{ab}$ & $119.50 \pm 31.40 \mathrm{~b}$ & 6.586 & $<0.001$ \\
\hline $\mathrm{HDL}[\mathrm{mg} / \mathrm{dL}]$ & $55.17 \pm 11.4$ & $32.76 \pm 9.6 \mathrm{a}$ & $37.71 \pm 7.7 \mathrm{a}$ & $49.67 \pm 11.4 \mathrm{bc}$ & $50.80 \pm 11.50 \mathrm{bc}$ & 8.314 & $<0.001$ \\
\hline $\mathrm{LDL}[\mathrm{mg} / \mathrm{dL}]$ & $40.33 \pm 10.6$ & $178.4 \pm 32.6 \mathrm{a}$ & $121.61 \pm 31.3 \mathrm{ab}$ & $69.67 \pm 14.3 \mathrm{abc}$ & $61.81 \pm 12.80 \mathrm{abc}$ & 61.400 & $<0.001$ \\
\hline
\end{tabular}

Using: One Way Analysis of Variance; Post HOC Test, LSD: a. Significant difference with CS 16w; b. Significant difference with HCHF; c. Significant difference with curcumin; d. Significant difference with A Tor; This table shows statistically significant difference between groups according to TC, TG, HDL and LDL.

Table [5]: Effect of curcumin, Atorvastatin and combination of them on malondialdehyde and SBP.

\begin{tabular}{|l|c|c|c|c|c|c|c|}
\hline & $\begin{array}{c}\text { CS 16w } \\
{[n=10]}\end{array}$ & $\begin{array}{c}\text { HCHF } \\
{[\mathrm{n}=10]}\end{array}$ & $\begin{array}{c}\text { Curcumin } \\
{[\mathrm{n}=10]}\end{array}$ & $\begin{array}{c}\text { A Tor } \\
{[\mathrm{n}=10]}\end{array}$ & $\begin{array}{c}\text { Curcumin }+ \text { A Tor } \\
{[\mathrm{n}=10]}\end{array}$ & ANOVA & $\begin{array}{c}\mathrm{p}- \\
\text { value }\end{array}$ \\
\hline Malondialdehyde & $10.99 \pm 0.22$ & $40.18 \pm 0.28 \mathrm{a}$ & $33.50 \pm 0.40 \mathrm{ab}$ & $31.50 \pm 0.35 \mathrm{ab}$ & $27.80 \pm 0.80 \mathrm{abcd}$ & 683.312 & $<0.001$ \\
\hline SBP $[\mathrm{mm} / \mathrm{Hg}]$ & $95.63 \pm 3.2$ & $142.50 \pm 9.22 \mathrm{a}$ & $117.70 \pm 4.75 \mathrm{ab}$ & $119.50 \pm 9.26 \mathrm{ab}$ & $109.60 \pm 6.75 \mathrm{abd}$ & 58.454 & $<0.001$ \\
\hline
\end{tabular}

Using: One Way Analysis of Variance; Post HOC Test, LSD: a. Significant difference with CS 16w; b. Significant difference with HCHF; c. Significant difference with curcumin; d. Significant difference with A Tor; This table shows statistically significant difference between groups according to malondialdehyde and SBP.

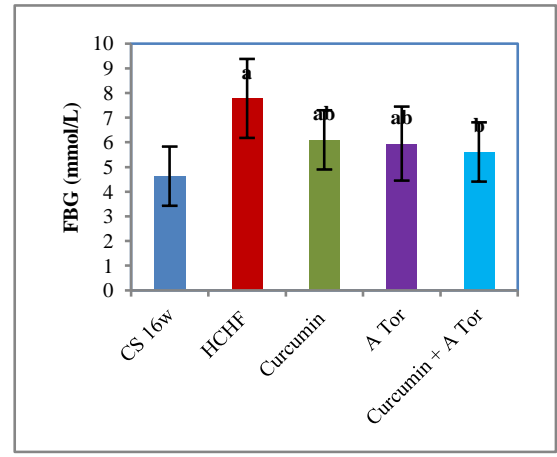

Figure [1]: Effect of curcumin, atorvastatin and combination of them on BG.

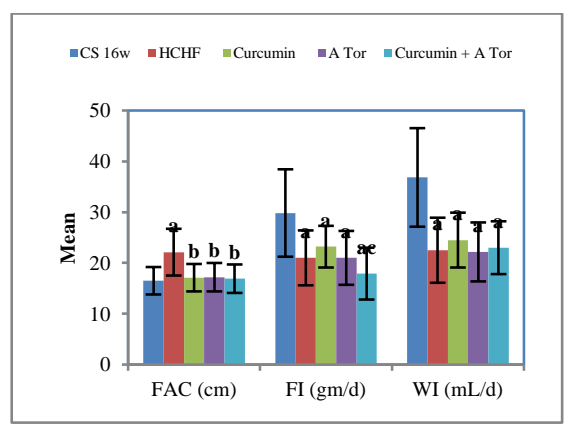

Figure [4]: Effect of curcumin, atorvastatin and combination of them on FAC, Fl and WI.

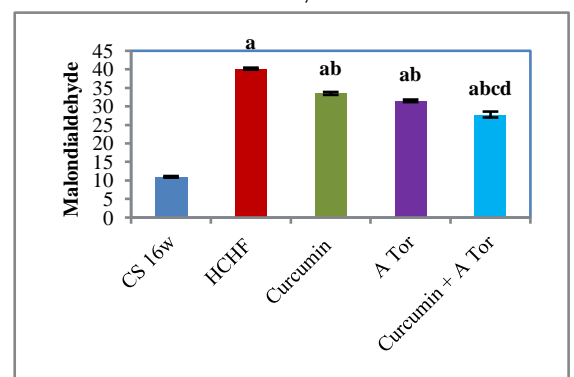

Figure [7]: Effect of curcumin, atorvastatin and combination on malondialdehyde

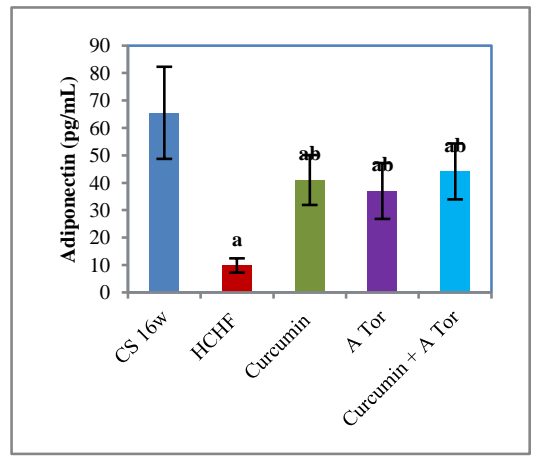

Figure [2]: Effect of curcumin, atorvastatin and combination of them on adiponectin $[\mathrm{pg} / \mathrm{mL}]$.

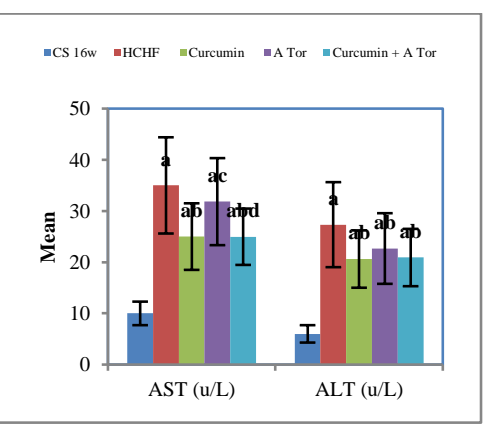

Figure [5]: Effect of curcumin, atorvastatin and combination of them on AST and ALT.

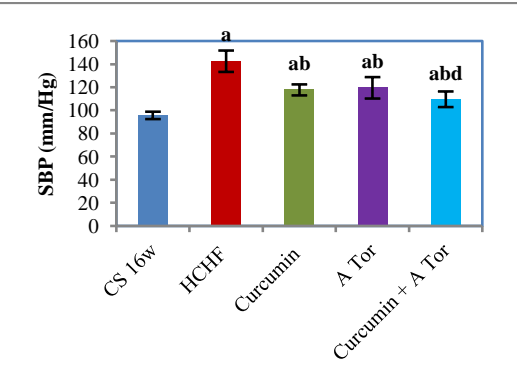

Figure [8]: Effect of curcumin, atorvastatin of them on $\mathrm{SBP}[\mathrm{mm} / \mathrm{Hg}]$.

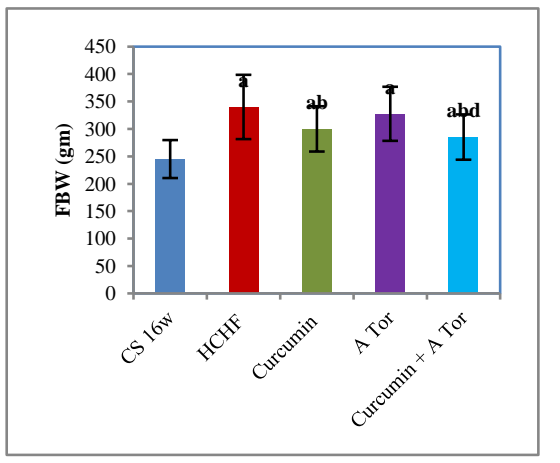

Figure [3]: Effect of curcumin, atorvastatin and on FBW

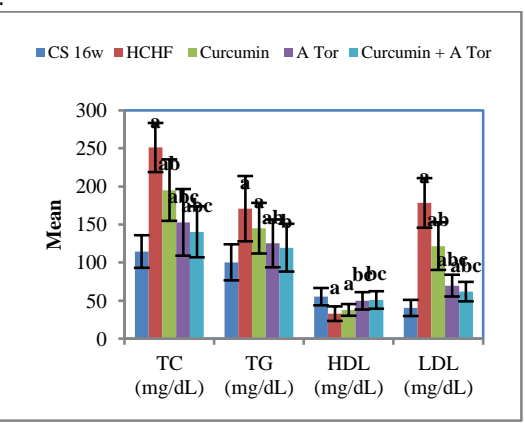

Figure [6]: Effect of curcumin, atorvastatin and combination of them on TC, TG, HDL, and LDL. 


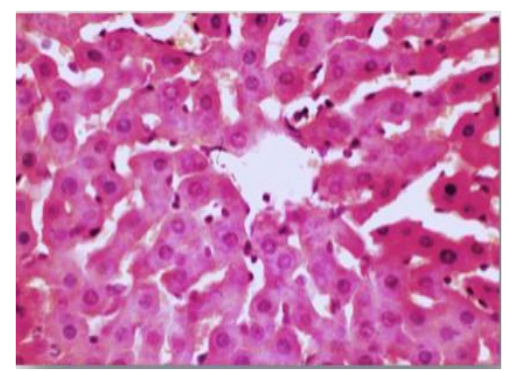

Figure [9]: Histopathological image from the CS group

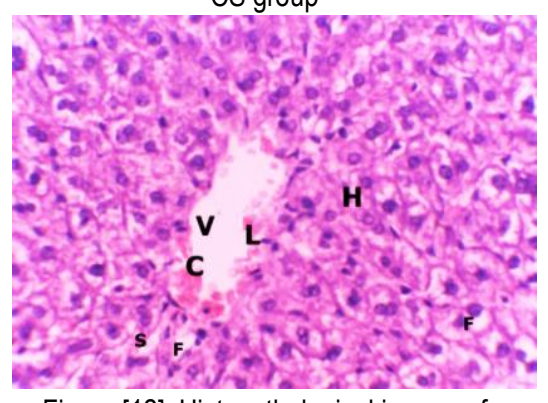

Figure [12]: Histopathological image of curcumin-treated group

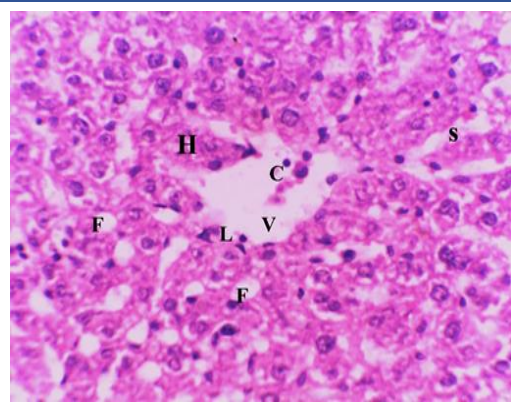

Figure [10]: Histopathological image from $\mathrm{HCHF}$ group

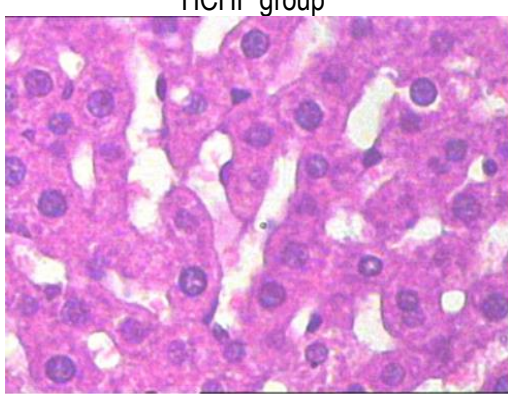

Figure [13]: Histopathological image from curcumin plus atorvastatin treated group

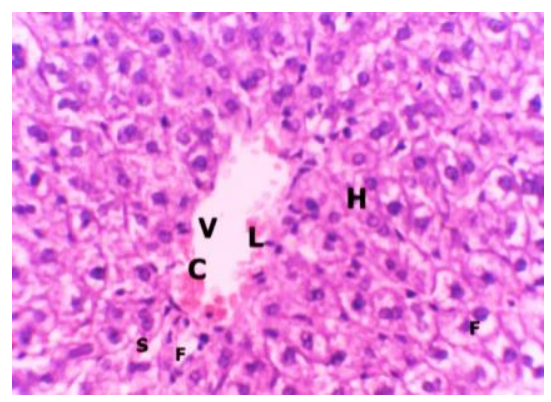

Figure [11]: Histopathological image of atorvastatin-treated group

\section{DISCUSSION}

Metabolic syndrome is the clustering of a multitude of cardiometabolic symptoms including central obesity, hypertension, insulin resistance, chronic low-grade inflammation and atherogenic dyslipidemia [12]. No medication is presently shown for the treatment of NAFLD/NASH. The standard care is represented by lifestyle intervention. However, because this approach has several limitations, such as a lack of compliance, the use of many drugs has been proposed [13].

In this study, we assessed the effect of curcumin, and atorvastatin either alone or in combination in a high carbohydrate high fat [HCHF] diet model of metabolic syndrome. The HCHF diet successfully generated a phenotype associated with diet-induced metabolic syndrome, including obesity, metabolic abnormalities, hypertension and ectopic fat deposition in the liver. The findings of this study indicate that the high dose of curcumin administered daily to rats which diet-induced metabolic syndrome was able to normalize SBP, lower visceral adiposity and reduce inflammation, and reduce body weight or total body fat content which conflicted with the majority of similar studies [14]. Young male Sprague-Dawley rats fed [HCHF] diet in comparison with corn starch [CS] diet that contained the same number of carbohydrates showed significant increase in glucose levels together with marked increase in insulin resistance and with reduced serum adiponectin, significant decrease in food and water intake, with a greater FBW and FAC, dyslipidemia in the form of elevated plasma TC, TG, and LDL cholesterol with reduced plasma level of high- density lipoprotein [HDL] cholesterol, in addition HCHF diet produced significant increase in serum alanine transaminase [ALT] and aspartate transaminase [AST]. Also, in this study liver of rats fed HCHF diet showed who used [HCHF] diet model of metabolic syndrome but in rats [15].

In present study we tried to test [HCHF] diet model of metabolic syndrome in Sprague- Dawley rats. Several previous studies test the drugs on NAFLD/NASH used several dietary models for the disease; mainly high gat [HF] diet model, and Methionine and Choline deficient diet model. Such results occurred with HCHF diet, but not in CS diet, however both of them contained the same number of carbohydrates, but the carbohydrate components were different in their type. The [CS] diet contains a slowly digestible starch [15]. 
On the other hand, fructose and fat present in the [HCHF] diet, produced changes in metabolic variables, and liver structure and function. In this study, dyslipidemia can be explained by NASH associated with visceral obesity, insulin resistance and adipokines such as TNF- $a$ that increases FFA releases from adipocytes with consequent enhancement of lipid delivery to the liver [16].

Treating rats with atorvastatin $30 \mathrm{mg} / \mathrm{kg} /$ daydecreased plasma glucose, but in lesser extent to that with combination therapy, beside that atorvastatin significantly improved homeostasis model assessment [HOMA] of insulin resistance. Treating rats with curcumin $200 \mathrm{mg} / \mathrm{kg} /$ day-decreased plasma glucose, but in lesser extent to that with combination therapy too. These results were consistent with the pervious study by Huptas et al. and Matafome et al. [17,18] that evaluated the effect of 6 weeks of atorvastatin in insulin-resistant subjects and found that atorvastatin resulted in a significant reduction in glucose. On the other hand, it was observed that atorvastatin has no effect on insulin resistance in dyslipidemic patients [19].

In this study, atorvastatin can improve hyperglycemia and insulin resistance, that could be attributed to the elevation of both plasma insulin growth factor 1 [IGF- 1] and its mRNA expression in the liver. IGF-1, an important metabolic regulatory hormone synthesized and released mainly by the liver, has beneficial effects on glucose homeostasis due to its glucose lowering and insulin- sensitizing action [20]. IGF-1 has hypoglycemic effects and enhances insulin sensitivity. In skeletal muscle cells of type 2 diabetic patients, IGF-1 was found to be a more potent stimulant of glucose transport than insulin itself [21].

Treating rats with atorvastatin produced significant increase in the levels of adiponectin that was in consistency with balance-colio [22] who found that, three months of $10 \mathrm{mg} / \mathrm{d}$ atorvastatin increased the level of adiponectin in human beings with hypercholesterolemia and ischemic heart disease. Such results may be due to atorvastatin ability to increase adiponectin production and secretion in adipocytes. On the other hand, Shetty et al. [23] found that atorvastatin had no effect on circulating adiponectin levels in patient with diabetes.

In the current work, treating rats with curcumin increased serum adiponectin significantly. That was in accordance with Ding et al. [14], and Um et al. [24]

In addition, atorvastatin significantly decreased FAC, but it can't significantly decrease FBW, $\mathrm{FI}$ and WI. However, the Combination of curcumin and atorvastatin in the same previous doses decreased both FAC and FBW significantly with none significant reduction in FI or WI. Matafome et al. [18] reported that atorvastatin therapy cannot affect FBW.

Elevated liver enzymes can be explained by NASH associated damage to the liver cells caused by ALT and AST to leak into the blood stream [25].

In the current work, treating rats with curcumin was associated with significant reduction of liver enzymes, that agrees with previous reports [26-28].

In this study dyslipidemia can be explained by NASH associated with visceral obesity, insulin resistance and adipokines such as tumor necrosis alpha [TNF-a] that increases free fatty acids [FFA] release from adipocytes with enhancement of lipid delivery to the liver [16].

The obtained results revealed that, curcumin in rats fed high cholesterol diet resulted in reduction of lipid profile. Curcumin might decrease absorption of cholesterol and increase the activity of cholesterol7a-hydroxylase [29].

Treating rats with atorvastatin significantly reduced TC, TG, and LDL-C with increased HDL-C that was in agreement with previous study of Hernandez et al. [30], who stated that atorvastatin, an inhibitor of [HMG-CoA] reductase decreased hepatic triglyceride secretion without an increase in hepatic triglyceride concentration beside reduction of hepatic FFA and the cholesteryl ester availability derived from newly synthesized cholesterol that limits the secretion of VLDL cholesterol. Also, adiponectin, induced by atorvastatin, directly stimulates AMP-activated protein kinase [AMPK] and prevents hepatic lipid accumulation by increasing $\beta$-oxidation of free fatty acids and by 
diminishing their de novo synthesis [31].

HCHF diet feeding had induced hypertension in all of the HCHF diet groups, whereas the corn starch diet groups remained normotensive as in previous studies with this model [32].

The findings of this study indicate that the high dose of curcumin administered daily to rats with diet-induced metabolic syndrome was able to normalize SBP, lower visceral adiposity and reduce inflammation, and reduce body weight or total body fat content which conflicted with the majority of similar studies [14].

The high dose of atorvastatin administered daily for 16-weeks, led to a decrease in SBP independently of the lipid lowering effect, changes in endothelial function and oxidative stress. This is in agreement with wassmann and nickenig [33].

Conclusion: we recommend the use of curcumin if the prominent feature in NASH is insulin resistance while use atorvastatin if the prominent feature is dyslipidemia, and both drugs in combination if there are both dyslipidemia and insulin resistance. Future studies are recommended to test for the safety of both drugs and to calculate the minimum effective dose of both drugs in human being. Therefore, in our opinion, curcumin remains a promising drug for the treatment of NAFLD due to its metabolic effects and safety profile.

Financial and Non-Financial Relationships and Activities of Interest

None

\section{REFERENCES}

1. Simmons RK, Alberti KG, Gale EA, Colagiuri S, Tuomilehto J, Qiao $Q$, et al. The metabolic syndrome: useful concept or clinical tool? Report of a WHO Expert Consultation. Diabetologia. 2010 Apr; 53(4):600-5. [DOI: 10.1007/s00125-009-1620-4].

2. Ervin RB. Prevalence of metabolic syndrome among adults 20 years of age and over, by sex, age, race and ethnicity, and body mass index: United States, 2003-2006. Natl Health Stat Report. 2009 May 5;(13):1-7. [PMID: 19634296].

3. Li S, Yuan W, Deng G, Wang P, Yang P, Aggarwal BB.
Chemical Composition and Product Quality Control of Turmeric [Curcuma longa L.]: National Center for Pharmaceutical Crops. 2011; 2: 28-54.

4. Orellana-Paucar AM, Serruys AS, Afrikanova T, Maes J, De Borggraeve W, Alen J, et al. Anticonvulsant activity of bisabolene sesquiterpenoids of Curcuma longa in zebrafish and mouse seizure models. Epilepsy Behav. 2012; 24(1):14-22. [DOI: 10.1016/j.yebeh.2012.02.020].

5. Ebrahim S, Taylor FC, Brindle P. Statins for the primary prevention of cardiovascular disease. BMJ. 2014 Jan 27; 348: g280. [DOI: 10.1136/bmj. g280].

6. Papiez MA, Kaja M, Gebarowska A. Age-dependent different action of curcumin in thyroid of rat. Folia Histochem Cytobiol. 2008;46(2):205-11. [DOI: 10.2478/ v10042-008-0031-6].

7. Poudyal H, Campbell F, Brown L. Olive leaf extract attenuates cardiac, hepatic, and metabolic changes in high carbohydrate-, high fat-fed rats. J Nutr. 2010 May; 140 (5):946-53. [DOI: 10.3945/jn.109.117812].

8. Panchal SK, Poudyal H, lyer A, Nazer R, Alam MA, Diwan V, Kauter K, Sernia C, Campbell F, Ward L, Gobe G, Fenning A, Brown L. High-carbohydrate, high-fat dietinduced metabolic syndrome and cardiovascular remodeling in rats. J Cardiovasc Pharmacol. 2011;57 (5):611-24. [DOI: 10.1097/FJC.0b013e31821b1379].

9. Huang C, Cen C, Wang C, Zhan H, Ding X. Synergistic effects of colchicine combined with atorvastatin in rats with hyperlipidemia. Lipids Health Dis. 2014 Apr 17; 13:67. [DOI: 10.1186/1476-511X-13-67].

10. Panchal SK, Brown L. Rodent models for metabolic syndrome research. J Biomed Biotechnol. $2011 ; 2011$ : 351982. [DOI: 10.1155/2011/351982].

11. Leclercq IA, Farrell $G C$, Sempoux $C$, dela Peña $A$, Horsmans $Y$. Curcumin inhibits NF-kappaB activation and reduces the severity of experimental steatohepatitis in mice. J Hepatol. 2004 Dec;41(6):926-34. [DOI: 10.1016/ j. jhep.2004.08.010].

12. Grundy SM, Brewer HB Jr, Cleeman JI, Smith SC Jr, Lenfant C; National Heart, Lung, and Blood Institute; American Heart Association. Definition of metabolic syndrome: report of the National Heart, Lung, and Blood Institute/American Heart Association conference on scientific issues related to definition. Arterioscler Thromb Vasc Biol. 2004 Feb;24(2): e13-8. [DOI: 10.1161/01. ATV. 0000111245.75752.C6].

13. Pastori D, Polimeni L, Baratta F, Pani A, Del Ben M, Angelico $F$. The efficacy and safety of statins for the treatment of non-alcoholic fatty liver disease. Dig Liver Dis. 2015;47(1):4-11. [DOI: 10.1016/j.dld.2014.07.170].

14. Ding L, Li J, Song B, Xiao X, Zhang B, Qi M, Huang W, Yang $L$, Wang $Z$. Curcumin rescues high fat diet-induced obesity and insulin sensitivity in mice through regulating SREBP pathway. Toxicol Appl Pharmacol. 2016 Aug 1; 
304: 99-109. [DOI: 10.1016/j.taap.2016.05.011].

15. Poudyal H, Campbell F, Brown L. Olive leaf extract attenuates cardiac, hepatic, and metabolic changes in high carbohydrate-, high fat-fed rats. J Nutr. 2010 May; 140(5):946-53. [DOI: 10.3945/jn.109.117812].

16. Browning JD, Horton JD. Molecular mediators of hepatic steatosis and liver injury. J Clin Invest. 2004 Jul;114 (2): 147-52. [DOI: 10.1172/JCI22422].

17. Huptas S, Geiss HC, Otto C, Parhofer KG. Effect of atorvastatin (10 mg/day) on glucose metabolism in patients with the metabolic syndrome. Am J Cardiol. 2006 Jul 1; 98(1):66-9. [DOI: 10.1016/j.amjcard.2006.01.055].

18. Matafome $P$, Nunes $E$, Louro $T$, Amaral $C$, Crisóstomo J, Rodrigues $\mathrm{L}$, et al. A role for atorvastatin and insulin combination in protecting from liver injury in a model of type 2 diabetes with hyperlipidemia. Naunyn Schmiedebergs Arch Pharmacol. 2009 Mar; 379 (3): 24151. [DOI: 10.1007/s00210-008-0363-y].

19. Bayes B, Granada ML, Lauzurica R, Pastor MC, Navarro M, Bonet J, Llopis MA, Romero R. Effect of low doses of atorvastatin on adiponectin, glucose homeostasis, and clinical inflammatory markers in kidney transplant recipients. Transplant Proc. 2005 Nov; 37 (9): 3808-12. [DOI: 10.1016/j.transproceed.2005.08.064].

20. Frystyk J. Free insulin-like growth factors -measurements and relationships to growth hormone secretion and glucose homeostasis. Growth Horm IGF Res. 2004 Oct;14(5):337-75. [DOI: 10.1016/j.ghir.2004. 06.001].

21. Ciaraldi TP, Carter L, Rehman N, Mohideen $P$, Mudaliar $S$, Henry RR. Insulin and insulin-like growth factor-1 action on human skeletal muscle: preferential effects of insulinlike growth factor-1 in type 2 diabetic subjects. Metabolism. 2002 Sep;51(9):1171-9. [DOI: 10.1053/meta. 2002.34050].

22. Blanco-Colio LM, Martín-Ventura JL, Gómez-Guerrero C, Masramon X, de Teresa E, Farsang C, et al. Adiponectin plasma levels are increased by atorvastatin treatment in subjects at high cardiovascular risk. Eur J Pharmacol. 2008 May 31; 586 (1-3): 259-65. [DOI: 10.1016/j.ejphar. 2008. 02.042].

23. Shetty GK, Economides PA, Horton ES, Mantzoros CS, Veves A. Circulating adiponectin and resistin levels in relation to metabolic factors, inflammatory markers, and vascular reactivity in diabetic patients and subjects at risk for diabetes. Diabetes Care. 2004 Oct;27(10):2450-7. [DOI: 10.2337/diacare.27.10.2450].

24. Um MY, Hwang KH, Ahn J, Ha TY. Curcumin attenuates diet-induced hepatic steatosis by activating AMP-activated protein kinase. Basic Clin Pharmacol Toxicol. 2013 Sep; 113(3):152-7. [DOI: 10.1111/bcpt.12076].

25. Sato A, Kawano H, Notsu T, Ohta M, Nakakuki M, Mizuguchi K, Itoh M, Suganami T, Ogawa Y. Antiobesity effect of eicosapentaenoic acid in high-fat/high-sucrose diet-induced obesity: importance of hepatic lipogenesis. Diabetes. 2010 Oct;59(10):2495-504. [DOI: 10.2337/ db09-1554].

26. Maithilikarpagaselvi N, Sridhar MG, Swaminathan RP, Zachariah B. Curcumin prevents inflammatory response, oxidative stress and insulin resistance in high fructose fed male Wistar rats: Potential role of serine kinases. Chem Biol Interact. 2016 Jan 25; 244:187-94. [DOI: 10.1016/ j.cbi.2015.12.012].

27. Ahn J, Lee H, Kim S, Ha T. Curcumin-induced suppression of adipogenic differentiation is accompanied by activation of Wnt/beta-catenin signaling. Am J Physiol Cell Physiol. 2010; 298 (6): C1510-6. [DOI: 10.1152/ajpcell.00369. 2009].

28. Hyogo $\mathrm{H}$, Tazuma S, Arihiro $\mathrm{K}$, Iwamoto $\mathrm{K}$, Nabeshima $\mathrm{Y}$, Inoue M, Ishitobi T, Nonaka M, Chayama K. Efficacy of atorvastatin for the treatment of nonalcoholic steatohepatitis with dyslipidemia. Metabolism. 2008; 57(12):1711-8. [DOI: 10.1016/j.metabol.2008.07.030].

29. Feng D, Ohlsson L, Duan RD. Curcumin inhibits cholesterol uptake in Caco-2 cells by down-regulation of NPC1L1 expression. Lipids Health Dis. 2010 Apr 19; 9:40. [DOI: 10.1186/1476-511X-9-40].

30. Hernandez TL, Capell WH, Wolfe P, Gerard LA, Eckel RH. Time course of $\mathrm{C}$-reactive protein reduction with simvastatin therapy in patients with type 2 diabetes mellitus. Am J Cardiol. 2006 Dec 15;98(12):1656-9. [DOI: 10.1016/j.amjcard.2006.07.047].

31. Mazza A, Fruci B, Garinis GA, Giuliano S, Malaguarnera $\mathrm{R}$, Belfiore $\mathrm{A}$. The role of metformin in the management of NAFLD. Exp Diabetes Res. 2012; 2012:716404. [DOI: 10.1155/2012/716404].

32. Bhaswant M, Poudyal H, Mathai ML, Ward LC, Mouatt $P$, Brown L. Green and Black Cardamom in a Diet-Induced Rat Model of Metabolic Syndrome. Nutrients. 2015 Sep 11;7(9):7691-707. [DOI: 10.3390/nu7095360].

33. Wassmann S, Nickenig G. Interrelationship of free oxygen radicals and endothelial dysfunction--modulation by statins. Endothelium. 2003;10(1):23-33. [DOI: 10.1080/ 10623320303357 

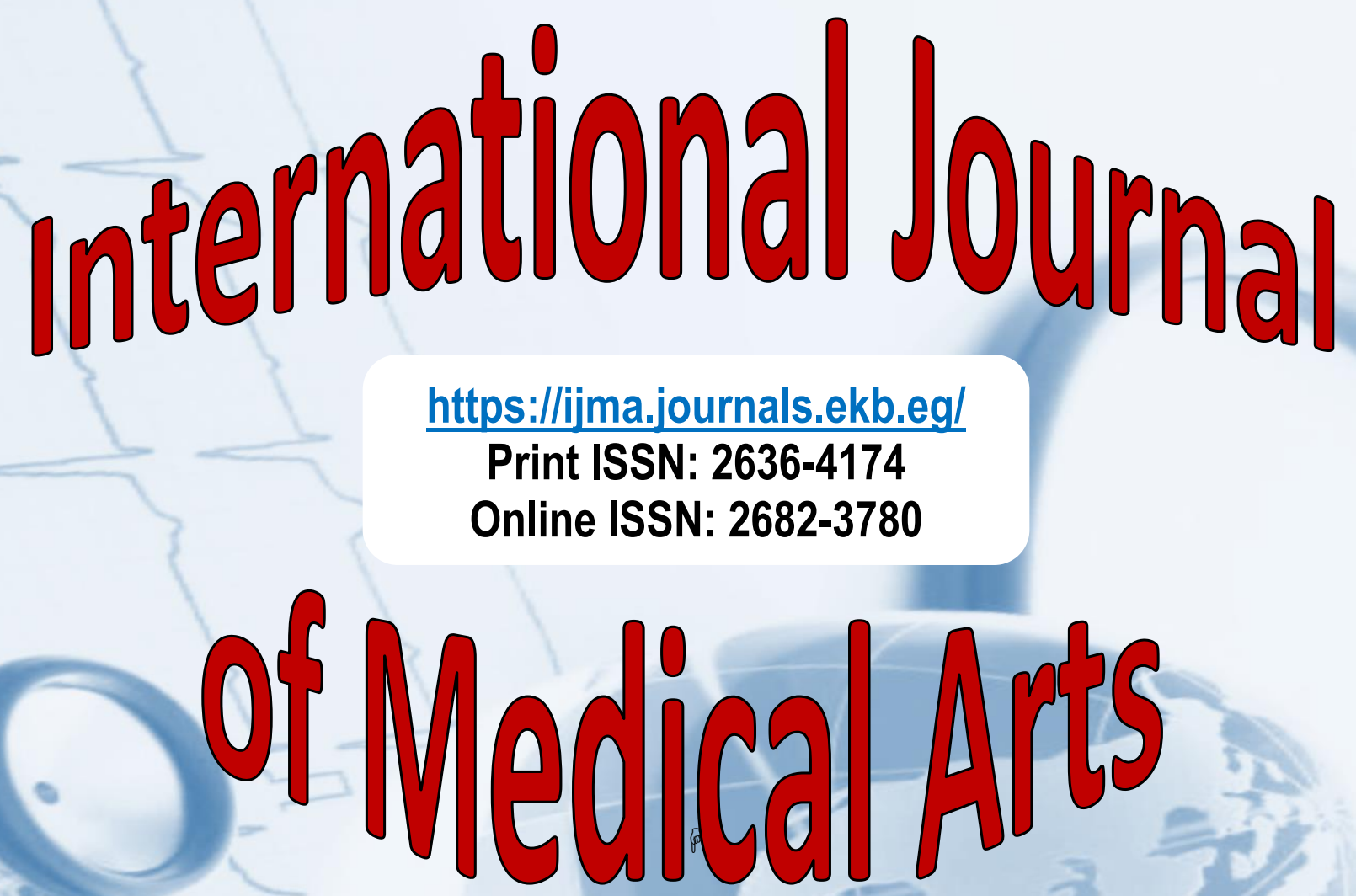